\title{
Evaluation Of A Targeted Prescriber Education Intervention On Emergency \\ Department Discharge Oxycodone Prescribing.
}

Ms. Síne R Donaldson, BN, Grad Cert Critical Care, MPH

Associate Nurse Unit Manager - Emergency Department

Mr. Andrew M Harding, BPharm, MPH

Senior Pharmacist - Emergency Medicine

Dr. Simone E Taylor, PharmD (BPharm), Grad Cert Clinical Research Methods

Senior Pharmacist - Emergency Medicine and Research

Dr. Hassan Vally BSc(Hons), PhD MAppEpid Grad Cert(Higher Education)

Senior Lecturer, School of Psychology and Public Health. La Trobe University.

Dr. Shaun L Greene, MBBS, MSc, FACEM

Emergency Physician and Clinical Toxicologist, Austin Hospital Clinical Toxicology

Service. Fellow of the University of Melbourne, Faculty of Medicine, Dentistry and Health Sciences.

This is the author manuscript accepted for publication and has undergone full peer review but has not been through the copyediting, typesetting, pagination and proofreading process, which may lead to differences between this version and the Version of Record. Please cite this article as doi: $10.1111 / 1742-6723.12772$

This article is protected by copyright. All rights reserved. 


\section{Author contributions}

SD -study and intervention design, data collection and analysis, primary drafting of manuscript

$\mathrm{AH}$-study and intervention design, intervention delivery, review of analysis and drafting manuscript

ST -study design, analysis and primary drafting manuscript

$\mathrm{HV}$-study design, review of analysis and drafting manuscript

SG - study and intervention design, intervention delivery, review of analysis and drafting manuscript

\section{Institutions where work carried out:}

Austin Health Emergency Department, Studley Road, Heidelberg, Victoria 3084, Australia

School of Psychology and Public Health, La Trobe University, Melbourne, Victoria 300, Australia

\section{Corresponding author:}

Dr. Shaun Greene,

Austin Health Emergency Department, PO Box 5555, Heidelberg. Australia Shaun.Greene@austin.org.au

Ph: (03) 9496 4509. Mobile 0431734607

Word count: Abstract: $250 \quad$ Main text: 2497 


\begin{abstract}
Objectives:

To evaluate the impact of an educational intervention on Emergency Department (ED) discharge opioid analgesic (OA) prescribing.
\end{abstract}

\title{
Methods:
}

A brief, one-on-one, educational intervention was delivered to ED OA prescribers by an ED clinical champion. The percentage of patients receiving (1) written advice regarding appropriate oxycodone use, (2) written or verbal advice regarding appropriate post-discharge follow-up, and (3) written GP notification that oxycodone had been prescribed were determined pre- and post-intervention, via review of electronic patient records and structured patient telephone interviews conducted 3-7 days after ED attendance. Secondary outcomes included total amount prescribed and use of non-OA therapies. ED OA prescribers were surveyed to evaluate perceived effectiveness and intervention acceptability.

\section{Results:}

Thirty ED OA prescribers received the 5-minute intervention. Pre- and postintervention, 80 and 81 patients were interviewed, respectively. Percentage of patients given written OA information increased from $10 \%$ to $22 \%(\mathrm{p}=0.04)$ and those receiving follow-up advice increased from $61 \%$ to $94 \%(\mathrm{p}<0.01)$. GP notification of OA prescription increased from $15 \%$ to $88 \%(\mathrm{p}<0.01)$. Risk ratio for achieving all three endpoints was 7.5 (95\% CI 1.8-32, p=0.01). Median total amount of oxycodone prescribed/patient decreased from $100 \mathrm{mg}$ to $50 \mathrm{mg}(\mathrm{p}=0.04)$. Non-OA therapies were used by $49 \%$ of pre-intervention and $85 \%$ of post-intervention patients $(p=<0.01)$. All ED OA prescribers agreed the intervention would change their prescribing practices; $70 \%$ deemed the intervention appropriate for delivery in their work environment. 


\section{Conclusion:}

A brief, one-on-one educational intervention targeting ED OA prescribers was well received by clinicians and associated with improved quality of OA prescribing.

\section{Key words:}

Analgesics, Opioid; Education, Medical; Emergency Department, Hospital;

Oxycodone; Pain Management; Practice Patterns, Physicians.

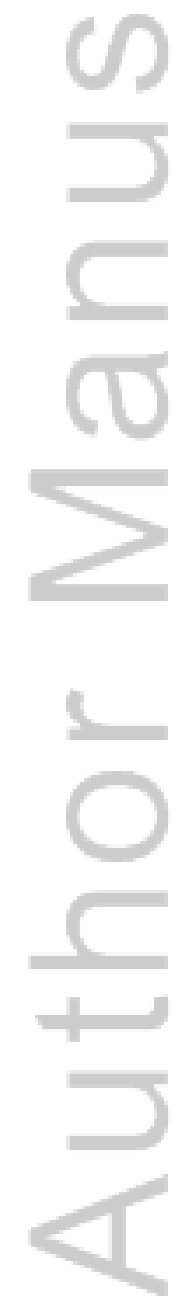

This article is protected by copyright. All rights reserved. 


\section{Introduction}

Oxycodone is approved in Australia for treatment of moderate to severe, acute or chronic pain. ${ }^{1}$ There has been a 22 -fold increase in the quantity of oxycodone supplied under the Pharmaceutical Benefits Scheme between 1997 and 2012. ${ }^{2}$ Many oxycodone prescriptions originate from hospital settings. Up to $10 \%$ of patients prescribed an Opioid Analgesic (OA) in a hospital setting for treatment of acute pain are still using an opioid one year later. ${ }^{3-5}$

OA prescribing rates have increased primarily due to a well-intentioned desire to improve the treatment of pain, however the increase has lead to evidence of harm, prompting both professional and public concern. ${ }^{2,6-9}$ There have been calls to improve the quality of opioid prescribing, including provision of patient information and notification of primary-care professionals following initiation of opioid therapy. ${ }^{10-14} \mathrm{~A}$ preliminary audit of prescribing practices in our Emergency Department (ED) revealed poor compliance with such recommendations. Numerous OAs are available for community treatment of pain, however in our hospital, oxycodone comprises over $90 \%$ of OA discharge or outpatient prescriptions. This study aimed to assess the impact of a brief, one-on-one educational intervention on improving oxycodone prescribing practices amongst ED prescribers.

\section{Methods}

\section{Setting}

This study was conducted in a major tertiary-referral metropolitan ED in Melbourne, Australia, with an annual attendance of 80000 patients. The study was approved by both the Austin Hospital and La Trobe University ethics committees. 


\section{Study Design}

A pre- and post- educational intervention study was conducted in two phases

(October-November 2013 and December 2014-February 2015). The intervention was delivered to ED oxycodone prescribers (OA prescribers), including ED consultants, registrars, residents, medical interns, and nurse practitioners. It comprised a fiveminute, one-on-one educational session given by a study investigator who was also an ED clinician (physician or pharmacist). The session was delivered at an opportunistic time when the intervention would not impact upon patient care; sessions commonly occurred at the beginning of an OA prescriber's clinical shift. Sessions involved a study investigator delivering the targeted Power Point ${ }^{\circledR}$ presentation (Appendix I) individually to an OA prescriber. The presentation contained specific, concise information regarding potential OA related harm in the community, the role OA prescribers play in this, optimal prescribing practice and examples of optimal patient discharge information. OA prescribers were made aware of the content and location of patient education resources, including a pain management patient information leaflet.

To evaluate the educational intervention, the impact on the patient prescribed an OA and the OA prescriber were investigated. The primary study endpoint was whether the patient prescribed oxycodone for use after leaving the ED received all three of the following: (1) written advice regarding the appropriate use of oxycodone, (2) written or verbal advice regarding appropriate follow-up after ED discharge, and (3) written notification to the patient's GP that oxycodone had been prescribed, the dose and indication. Secondary outcomes included total amount (in $\mathrm{mg}$ ) and number of doses of oxycodone prescribed, incidence of oxycodone-related adverse effects, whether 
prescribed oxycodone and other pain modalities were used after leaving ED and prescriber perceptions of whether the intervention would change their prescribing practice.

To evaluate the impact of the intervention on patient care, consenting adults prescribed oxycodone (immediate or slow release, single or combination product) by an ED OA prescriber for use after discharge, underwent a telephone interview within seven days of ED presentation. Patients were eligible if they self-administered their medications and spoke English. Patients who received ED care from a study investigator were excluded. Dose and duration of oxycodone prescribed was at the discretion of the treating clinician. In the post-intervention phase, only patients who met the above criteria, and were prescribed oxycodone by an OA prescriber that had received the educational intervention and completed the follow-up survey were eligible for the study. Data collection for patients prescribed an OA by a study prescriber commenced one week following delivery of the educational session.

Electronic patient records of sequential ED attendees were screened to identify potential study patients. Eligible patients were contacted three to seven days after receiving the oxycodone prescription. Patient consent was sought at the beginning of the telephone interview, not during the ED presentation, to minimize potential Hawthorne-effects. Sequential patient identification using electronic medical records continued until 80 patients had consented and participated in each phase. Interviews were conducted by an experienced ED nurse not involved in the patients' ED care. 
To evaluate prescriber perceptions of the intervention, within 7 days of receiving the intervention, OA prescribers were invited to complete an anonymous, voluntary questionnaire. Seven statements were presented regarding the intervention and OA prescribers were asked to rate their responses on a 5-point Likert scale. The statements addressed the educational information provided, appropriateness of the intervention, how it was delivered, and whether they deemed it would change their prescribing habits. A further section was available for additional comments. Not all ED prescribers were exposed to the study intervention due to the large number of OA prescribers and frequent staff rotation into and out of ED. A group of 30 prescribers was randomly selected to receive the intervention, and their prescribing practices were studied.

Statistical Analyses

No published literature was available to guide a sample size calculation using our primary endpoint. In a local retrospective audit of ED discharge summaries, $22 \%$ of patients had oxycodone mentioned in their discharge summary, a follow-up plan and when follow-up should occur. It was assumed that a similar proportion of preintervention patients would receive written information about oxycodone, follow-up advice and have a discharge summary informing the GP of the oxycodone prescription, dose and indication. A clinically significant increase was determined as having $50 \%$ of patients meeting this primary endpoint. To demonstrate a statistically significant change, 80 patients needed to be included in each of the pre- and postintervention periods (power 95\%, level of significance $0.05,2$-sided p-value). 
Descriptive statistics were used to summarise data. The Chi square test was used to compare proportions of patients receiving each separate, and all components of the primary endpoint. Continuous data was compared using the student t-test or the nonparametric Mann-Whitney U test, as appropriate. The level of significance was 0.05. All analyses were undertaken using Statistical Package for Social Sciences version 22.0 (SPSS; Chicago, IL).

\section{Results}

Pre-intervention, 209 consecutive ED patients attending over a 20-day period received an oxycodone prescription for use after ED discharge and were screened for study eligibility, in order to recruit 80 patients. Post-intervention, 592 consecutive ED patients attending over a 66-day period who received an oxycodone prescription for use after ED discharge were screened for study eligibility in order to recruit 81 postintervention patients. Patient recruitment into the study is outlined in figure 1 . The two patient groups were well matched for demographic parameters, with no statistically significant differences identified in patient age, gender or indication for analgesia (table 1). There was no significant difference between the pre and post intervention periods in terms of the total number of opioid prescriptions written.

As outlined in table 2, the proportion of patients who met all three components of the primary endpoint increased from $3 \%$ to $19 \%(\mathrm{p}<0.01)$, with a risk ratio of $7.5(95 \%$ CI $1.8-32, \mathrm{p}<0.01)$. The percentage of patients who received written information regarding oxycodone at the time of prescription increased from $10 \%$ to $22 \%(\mathrm{p}=0.04)$. The percentage of patients who reported being given information about follow-up increased from $61 \%$ to $94 \%(\mathrm{p}<0.01)$. Documentation in the patient's discharge 
summary regarding the prescription of oxycodone the dose and indication increased from $15 \%$ to $88 \%(\mathrm{p}<0.01)$.

The median total amount (dose unit x number of doses in $\mathrm{mg}$ ) of oxycodone prescribed per patient decreased from $100 \mathrm{mg}$ pre-intervention to $50 \mathrm{mg}$ postintervention $(\mathrm{p}=0.04)$.

In the pre- and post-intervention groups, $80 \%$ and $89 \%$ of patients, respectively, reported taking at least one dose of the oxycodone prescribed for them. Reasons that pre-intervention patients gave for not taking oxycodone after ED discharge included that it was not needed or they had had no pain since discharge $(11 / 16 ; 69 \%)$, the prescription had not been filled $(3 / 16 ; 19 \%)$ and they were concerned about side effects $(10 / 16 ; 63 \%)$. Post-intervention, the nine patients who had not taken their prescribed oxycodone after ED discharge explained that they had not needed it or had had no pain since leaving ED. Amongst patients who used oxycodone following ED discharge, the percentage who reported experiencing side-effects increased from $53 \%$ (34/64) pre-intervention to $85 \%$ (61/72) post-intervention (table 3). Significantly more patients reported using pain therapies other than oxycodone in the postintervention group $(69 / 81 ; 85 \%)$ than pre-intervention $(39 / 80 ; 49 \%)(\mathrm{p}<0.01)($ table 3). The percentage of patients using simple analgesia increased from $28 \%(22 / 80)$ to $70 \%(57 / 81)$ after the intervention $(\mathrm{p}<0.01)$. The use of non-drug treatments, such as heat/ice packs, Pilates and stretching, increased from $11 \%(9 / 80)$ to $26 \%(21 / 81)$ postintervention $(\mathrm{p}=0.02)$. 
All 30 OA prescribers who received the educational intervention completed the prescriber evaluation questionnaire. All OA prescribers either agreed or strongly agreed that their opioid prescribing practices would change as a result of the education session (table 4). Twenty-four $(80 \%)$ respondents stated that they were aware that current prescribing practices could contribute to opioid misuse in the community. Most prescribers $(28 / 30 ; 93 \%)$ agreed that the education session was an appropriate length of time for delivery in their work environment.

\section{Discussion}

Pain is a common presentation to ED and OAs are prescribed with good intentions to manage such pain after patients leave ED. There is a delicate balance between providing patients with medicines required to reduce pain and minimizing harm associated with inappropriate OA use. The importance of responsible OA prescribing has been recognized by regulatory and medical bodies as a key modifiable part of the opioid supply chain which could potentially reduce associated harm. ${ }^{10,15}$ There is no clear evidence linking suboptimal ED OA prescribing with subsequent harm. ${ }^{16}$ However, many barriers to optimal prescribing in ED exist, including high patient turnover, time pressures, large numbers of rotating staff, heterogeneous presentations involving both cancer and non-cancer pain, limited knowledge of patients' past medical history and limited tools to identify patients at higher risk of OA related harm. ${ }^{12}$ These barriers may allow ED prescribing to serve as a gateway for recurrent opioid use and may make EDs important sites for interventions designed to improve opioid prescribing. ${ }^{17-19}$

We have demonstrated that a brief targeted education intervention provided during an OA prescribers' clinical shift resulted in significantly more patients being provided 
with written information regarding oxycodone, being provided with follow-up advice regarding pain management after leaving ED and written GP notification regarding the prescription of oxycodone, its dose and indication. Most improvements were in the areas of GP notification and provision of follow-up recommendations. Provision of written information is an area of focus for further improvements.

Also associated with the education intervention was a larger proportion of patients actually filling and using their prescribed oxycodone, in addition to using other nonopioid pain management modalities in combination with the OA. These outcomes suggest that post-intervention patients were better informed about multi-modal optimal pain management. Post intervention patients also reported a greater prevalence of potential adverse effects due to the OA, including constipation and dizziness. This may be due to reporting bias, with these patients having a better understanding of potential adverse effects.

The content of our educational intervention was developed after considering published opioid prescribing guidelines developed by Australian and international government agencies, medical colleges and EDs. ${ }^{10,11,15,17}$ In 2013, the New York City Department of Health and Mental Hygiene and emergency physicians developed a prescribing guideline that recommended prescribing the lowest effective OA dose for only as many days as required, and promoted evidence-based pain management to maximize the benefit-risk ratio. ${ }^{20}$ The White House Office of National Drug Control Policy and others highlight the role of education, stating that pharmacists, prescribers and patients need education regarding the risks associated with high dose OAs, including dependence and overdose. ${ }^{21}$ Our educational intervention emphasized 
potential OA-associated harms, how to prescribe safely and the importance of educating patients about optimal pain management principles and potential adverse effects. $^{22}$

Traditional models of delivering education can be challenging in a busy ED setting. The need for OA prescribers to be part of a 24 hour, seven day a week workforce, limits the feasibility of a single education session to reach all prescribers. After reviewing evidence regarding medical education delivery, our intervention was designed to be a one-on-one, interactive session delivered by an ED clinical champion in approximately five minutes, using minimal slides containing high impact information..$^{23-25} \mathrm{OA}$ prescribers were approached several days later to complete a questionnaire on the educational intervention, which provided an opportunity to reinforce key messages. Although the intervention was delivered during a clinical shift, OA prescribers did not consider that it negatively impacted on patient care. This intervention allowed education to be provided to a large number of OA prescribers at mutually convenient times, without the need to schedule a formal group education session. The intervention is easily replicable and could be instituted in other EDs.

Most OA prescribers reported they were already aware of health implications surrounding OA misuse, while only half stated they were aware of current OA prescribing best practice. Although OA prescribers may be aware of potential negative health implications of community opioid misuse, education is required to translate this knowledge into rational, safe prescribing practices. In addition, any educational intervention is likely to require ongoing investment of resources to monitor and maintain improved prescribing practices. 
Our intervention impacted upon selected aspects of opioid prescribing in our ED.

Future studies could focus on additional aspects including development and validation of risk tools to identify at-risk patients at the time of prescription, use of automated electronic prescribing warnings and dosing ceilings and automated GP notification of an opioid prescription.

To ensure sustainability of our findings, we propose that our brief intervention be incorporated into the orientation process for new prescribers in our ED and periodically included in departmental communications and education sessions.

\section{Limitations}

Our study has several limitations. It did not seek to ascertain whether improvements in the endpoints studied led to reduced OA-related harm, but the intervention is consistent with recommended opioid prescribing practices, therefore would be expected to limit such harm. There is the potential for reporter and prevarication bias where endpoints were reliant upon patient report and willingness to reveal information. In order to minimize a potential Hawthorne effect, patients were asked for consent at the time of the follow-up telephone interview, rather than during the ED presentation. In addition, prescribers were unaware that their prescribing habits were being evaluated. Recall bias is possible as patients were asked to recall information and events that occurred several days earlier. There is also potential for postintervention selection bias, as not all OA prescribers received the education intervention and the practices of those not receiving the intervention, in the postintervention period, were not evaluated. 


\section{Conclusion}

This study demonstrated that a short, one-on-one education intervention delivered to OA prescribers working in a metropolitan ED led to significant improvements in provision of written and verbal OA related information to patients and their GPs. In addition, patients received smaller amounts of OAs and were more likely to utilize other pain treatments. Although short, the educational intervention was well received and able to be delivered to OA prescribers during rostered clinical duties. Further study is required to evaluate whether this type of intervention ultimately leads to a reduction in recurrent $\mathrm{OA}$ use and OA-related harm.

\section{Acknowledgements}

The authors have no competing interests, relationships or financial disclosures or support in relation to this manuscript to declare.

The authors wish to thank Dr. Zeff Koutsogiannis for his assistance in study design and implementation. 


\section{References}

1. Australian Register of Therapeutic Goods (TGA). [Cited 19 Aug 2015.] Available from URL: https://www.ebs.tga.gov.au/ebs/picmi/picmirepository.nsf/PICMI?OpenForm $\& \mathrm{t}=$ pi\&q=Endone

2. Dobbin M. Pharmaceutical drug misuse in Australia. Aust Prescr. 2014;37: 79-81.

3. Alam A, Gomes T, Zheng H, Mamdani MM, Jurlink DN, Bell CM. Long-term analgesic use after low-risk surgery: a retrospective cohort study. Arch Intern Med. 2012;172:425-30.

4. Singh JA, Lewallen DG. Predictors of pain and use of pain medications following primary Total Hip Arthroplasty (THA): 5707 THAs at 2-years and 3289 THAs at 5-years. BMC Musculoskelet Discord. 2010;11:90-5.

5. Singh JA, Lewallen DG. Predictors of use of pain medications for persistent knee pain after primary Total Knee Arthroplasty: a cohort study using an institutional joint registry. Arthritis Res Ther. 2012;14:R248-54.

6. Pilgrim JL, Yafistham SP, Gaya S, Saar E, Drummer OH. An update on_oxycodone: lessons for death investigators in_Australia. Forensic Sci Med Pathol. 2015;11:3-12.

7. Shand FL, Campbell G, Hall W, Lintzeris N, Cohen M, Degenhardt L. Real time monitoring of Schedule 8 medicines in Australia: Evaluation in essential. Med J Aust. 2013;198:80-2.

8. Dwyer J. Coroners Court of Victoria. Coroners Prevention Unit. Drug overdose deaths in Inner North West Melbourne. Presentation to Yarra Drug Health Forum on pharmaceutical misuse. 2013. 
9. Rintoul AC, Dobbin MD, Drummer OH, Ozanne-Smith J. Increasing deaths involving oxycodone, Victoria, Australia, 2000-09. Inj Prev. 2011;17:254-9.

10. The Royal Australasian College of Physicians. Prescription opioid policy: improving management of chronic non-malignant pain and prevention problems associated with prescription opioid use. 2009. [Cited 19 Aug 2015.] Available from URL:

www.ranzcp.org/Files/ranzcpattachments/Resources/Submissions/CNMPpdf.aspx.

11. Hall WD, Farrell MP. Minimising the misuse of oxycodone and other pharmaceutical opioids in Australia. Med J Aust. 2011;19: 248-9

12. McDonough, M. Safe prescribing of opioids for persistent non-cancer pain. Australian Prescriber. 2012;35:20-4.

13. Roxburgh A, Bruno R, Larance B, Burns L. Prescription of opioid analgesics and related harms in Australia. Med J Aust. 2011;195:280-4.

14. Kripalani S, LeFevre F, Phillips CO, Williams MV, Basaviah P, Baker. Deficits in communication and information transfer between hospital-based and primary care physicians: implications for patient safety and continuity of care. JAMA.2007;297:831-41.

15. Harrison CM, Charles J, Henderson J, Britt H. Opioid prescribing in Australian general practice. Med J Aust. 2012;196:380-1.

16. Logan J, Liu Y, Paulozzi LJ, Zhang K, Jones C. Opioid prescribing in emergency departments: the prevalence of potentially inappropriate prescribing and misuse. Med Care. 2013; doi:10.1097.

17. Franklin, G. Opioids for chronic non cancer pain. American Academy of Neurology. 2014;83:1277-84. 
18. Hoppe J, Kim H, Heard K. Association of emergency department opioid initiation with recurrent opioid use. Ann Emerge Med. 2015:65;493-99.

19. Paulozzi LJ. Jones CM. Mack KA. Rudd RA. Vital signs: overdoses of prescription opioid pain relievers. United States, 1999-2008. Morbidity and Mortality Weekly Report. 2011;60:1487-92.

20. Kunins HV. Farley TA. Dowell D. Guidelines for opioid prescription; Why emergency physicians need support. Ann Intern Med. [Cited 6 May 2013.] Available from URL: http://annals.org

21. White House Office of National Drug Control Policy. (2011). Epidemic:

Responding to Americas Prescription Drug Abuse Crisis. https://www.whitehouse.gov/sites/default/files/ondcp/issuescontent/prescription-drugs/rx_abuse_plan.pdf

22. Darke, S. Oxycodone poisoning; Not just the usual suspects. Addiction. 2011; $106 ; 1035-6$

23. Satterlee WG, Eggers RG, Grimes DA. Effective medical education: insights from the Cochrane Library. Obstet Gynecol Surv. 2008;63:329-33.

24. Davis D, O'Brien MA, Freemantle N, Wolf FM, Mazmanian P, Taylor-Vaisey A. Impact of formal continuing medical education: do conferences, workshops, rounds, and other traditional continuing education activities change physician behavior or health care outcomes? JAMA. 1999;282:867-74.

25. Mansouri M, Lockyer J.J. Meta-analysis of continuing medical education effectiveness. Contin Educ Health Prof. 2007;27:6-15. 
Table 1: Patient demographic details

\begin{tabular}{|l|c|c|c|}
\hline \multicolumn{1}{|c|}{ Parameter } & $\begin{array}{c}\text { Pre-intervention, } \\
\mathrm{n}(\%)[\mathrm{N}=80]\end{array}$ & $\begin{array}{c}\text { Post-intervention, } \mathrm{n}(\%) \\
{[\mathrm{N}=81]}\end{array}$ & $\mathrm{p}$ \\
\hline Age, years, mean \pm s.d & $46 \pm 17$ & $46 \pm 17$ & $0.83^{*}$ \\
\hline Gender, male & $42(53)$ & $42(52)$ & $0.93^{\#}$ \\
\hline $\begin{array}{l}\text { Indication; } \\
\text { - Abdominal pain }\end{array}$ & $5(6 \%)$ & $10(12 \%)$ & \\
- Musculoskeletal pain & $59(74 \%)$ & $45(56 \%)$ & \\
- Renal colic & $6(8 \%)$ & $9(11 \%)$ & \\
- Other & $10(13 \%)$ & $17(21 \%)^{* *}$ & \\
\hline
\end{tabular}

*Student t-test, \# Chi square test, **includes one oncology patient, already on oxycodone

This article is protected by copyright. All rights reserved. 
Table 2: Quality of oxycodone prescribing (primary endpoint)

\begin{tabular}{|l|c|c|c|c|}
\hline \multicolumn{1}{|c|}{ Parameter } & $\begin{array}{c}\text { Pre- } \\
\text { intervention, } \\
\mathrm{n}(\%)[\mathrm{N}=80]\end{array}$ & $\begin{array}{c}\text { Post- } \\
\text { intervention, } \\
\mathrm{n}(\%)[\mathrm{N}=81]\end{array}$ & $\begin{array}{c}\text { Difference in } \\
\%(95 \% \\
\text { confidence } \\
\text { interval) }\end{array}$ & $\mathrm{p}^{*}$ \\
\hline $\begin{array}{l}\text { Given written information } \\
\text { about oxycodone }\end{array}$ & $8(10)$ & $18(22)$ & $\begin{array}{c}12 \% \\
(-0.2-25)\end{array}$ & 0.04 \\
\hline $\begin{array}{l}\text { Told to follow-up with GP if } \\
\text { more analgesia needed }\end{array}$ & $49(61)$ & $76(94)$ & $\begin{array}{c}33 \% \\
(19-46)\end{array}$ & $<0.01$ \\
\hline $\begin{array}{l}\text { Discharge summary for GP } \\
\text { state oxycodone product, } \\
\text { dose and indication for } \\
\text { prescription }\end{array}$ & $12(15)$ & $71(88)$ & $\begin{array}{c}73 \% \\
(61-85)\end{array}$ & $<0.01$ \\
\hline $\begin{array}{l}\text { All three of the above } \\
\text { parameters (primary } \\
\text { endpoint) }\end{array}$ & $2(3)$ & $15(19)$ & $\begin{array}{c}16 \% \\
(6-26)\end{array}$ & $<0.01$ \\
\hline
\end{tabular}

* Chi square test

This article is protected by copyright. All rights reserved. 
Table 3: Side effects experienced following oxycodone use and other therapies used

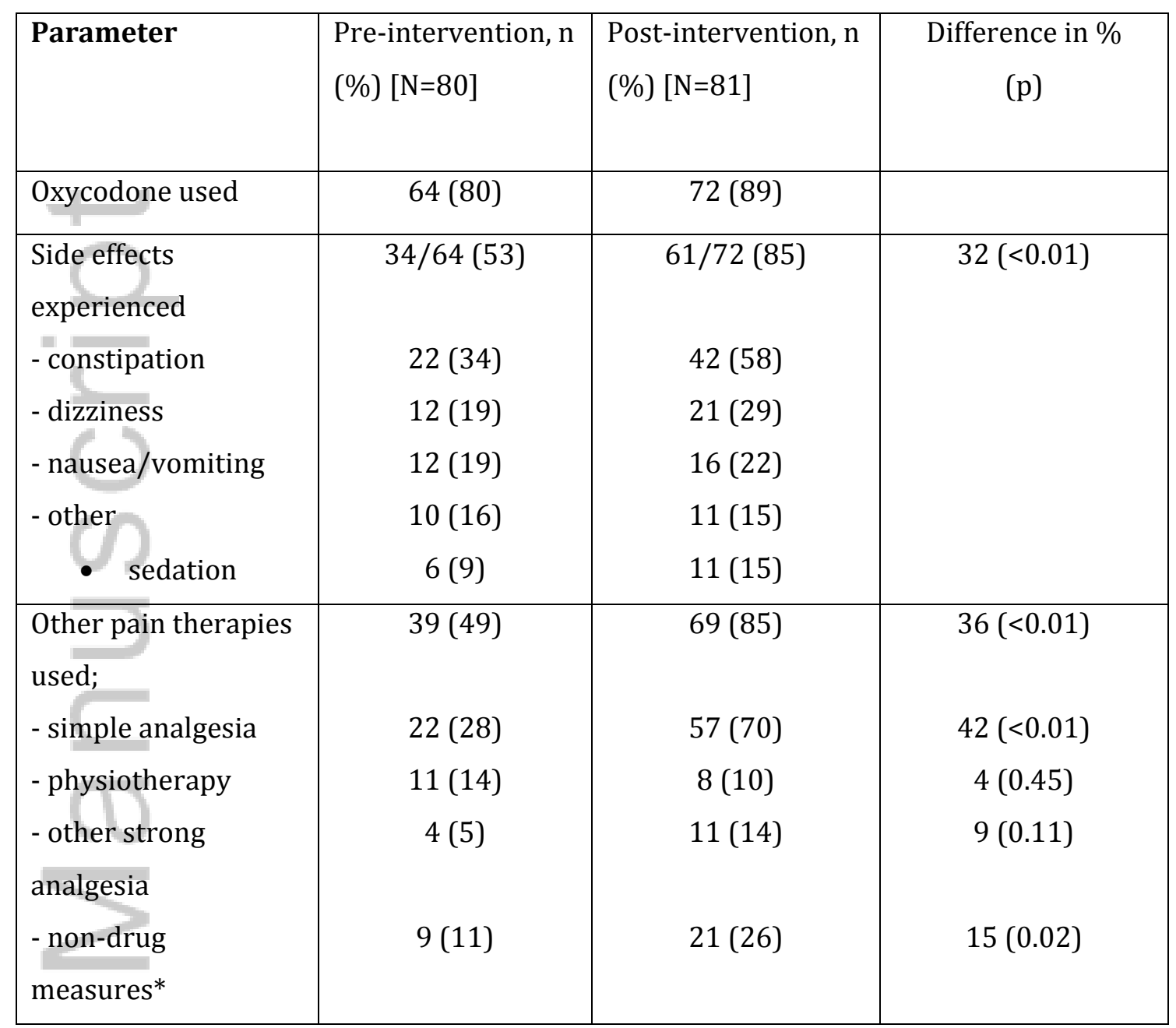

* e.g. heat/ice packs, pilates, stretches 
Table 4: Prescriber comments regarding the educational intervention

\section{Prescriber survey questions:}

1. The way that I prescribe opioids in the ED will change as a result of the opioid prescribing education session.

2. I was aware that the current practices of some prescribers might be contributing to the problems of prescription opioid analgesic abuse within the community.

3. I was aware of the information regarding best practice opioid analgesic prescribing presented in the opioid prescribing education session.

4. I was aware of all the health implications regarding prescription opioid analgesic use that were presented in the opioid prescribing education session.

5. The opioid prescribing education session was the appropriate length of time for my work environment.

6. I believe the opioid prescribing education session was interactive in nature.

7. Prescribers in the ED currently receive sufficient education regarding the prescription of opioid analgesics.

\begin{tabular}{|c|c|c|c|c|c|}
\hline \multirow{2}{*}{$\begin{array}{c}\text { Question } \\
\text { number }\end{array}$} & \multicolumn{5}{|c|}{ Number of responses (\%) } \\
\cline { 2 - 6 } & $\begin{array}{c}\text { Strongly } \\
\text { agree }\end{array}$ & Agree & $\begin{array}{c}\text { Neither } \\
\text { agree not } \\
\text { disagree }\end{array}$ & Disagree & $\begin{array}{c}\text { Strongly } \\
\text { disagree }\end{array}$ \\
\hline 1 & $10(33)$ & $20(67)$ & 0 & 0 & 0 \\
\hline 2 & $9(30)$ & $15(50)$ & $4(13)$ & $2(7)$ & 0 \\
\hline 3 & $7(23)$ & $9(30)$ & $7(23)$ & $7(23)$ & 0 \\
\hline 4 & $9(30)$ & $8(27)$ & $4(13)$ & $9(30)$ & 0 \\
\hline $5^{*}$ & $21(70)$ & $7(23)$ & 0 & $1(3)$ & 0 \\
\hline 6 & $20(67)$ & $9(30)$ & $1(3)$ & 0 & 0 \\
\hline 7 & $6(20)$ & $8(27)$ & $10(33)$ & $6(20)$ & 0 \\
\hline
\end{tabular}

* Not answered by one respondent 


\section{University Library}

\section{- M M I N E R VA \\ A gateway to Melbourne's research publications}

Minerva Access is the Institutional Repository of The University of Melbourne

Author/s:

Donaldson, SR;Harding, AM;Taylor, SE;Vally, H;Greene, SL

Title:

Evaluation of a targeted prescriber education intervention on emergency department discharge oxycodone prescribing

Date:

2017-08-01

Citation:

Donaldson, S. R., Harding, A. M., Taylor, S. E., Vally, H. \& Greene, S. L. (2017). Evaluation of a targeted prescriber education intervention on emergency department discharge oxycodone prescribing. EMERGENCY MEDICINE AUSTRALASIA, 29 (4), pp.400-406. https://doi.org/10.1111/1742-6723.12772.

Persistent Link:

http://hdl.handle.net/11343/292935 